\title{
Correlation of Body Mass Index and Health to Quality of Life among Medical Undergraduates
}

\author{
Sivanesan Supramaniyam ${ }^{1}$, Abdullah Firmansah W. ${ }^{2}$, Ellyana Sungkar ${ }^{3}$ \\ ${ }^{1}$ Faculty of Medicine, Universitas Padjadjaran, ${ }^{2}$ Department of Medical Nutrition, Faculty of \\ Medicine, Universitas Padjadjaran, ${ }^{3}$ Department of Physical Medicine and Rehabilitation, Faculty \\ of Medicine, Universitas Padjadjaran/Dr. Hasan Sadikin General Hospital Bandung
}

\begin{abstract}
Background: Overweight and obesity play a major role in an individual's Health with Quality of Life (HRQOL). Several studies reported that there are differences between the results in different communities since HRQOL score in relation to BMI is sensitive to specific communities. The aim of this study was to investigate the relationship between the Body Mass Index (BMI) and Health with Quality of Life among the Medical Undergraduates of Universitas Padjadjaran, Bandung

Methods: This study was an analytical cross-sectional study conducted from September to November 2012 in Faculty of Medicine Universitas Padjadjaran. A total of 280 respondents aged 16-30 were selected from the of 2009, 20102011 and 2012 classes of medical undergraduates after a thorough BMI screening. The overweight and obese subjects were selected using total sampling method, while subjects with normal BMI were sampled using simple random sampling. The subjects were asked to fill up Short Form 36 questionnaires. The correlation was assessed using Spearman`s Correlation test and the difference between the groups were analyzed using Kruskal-Wallis test.

Results: Of the 260 respondents, there was a weak correlation between the BMI and total health with the quality of life of the undergraduates ( $\mathrm{rho}=-0.173$ ). Among the eight scales used, there was no correlation shown in three scales, namely body pain, social function, and mental health, in any of the groups.

Conclusion: Increased body mass index impairs the health-related quality of life of the respondents, except in scales such as body pain, social function, and mental health.
\end{abstract}

Keywords: Body mass index, health related to quality of life, Short Form 36

\section{Introduction}

Overweight and obesity is a medical condition where there is an excessive deposition of fat in body that has deleterious effects on health. ${ }^{1}$ According to World Health Organization (WHO) global estimate 2008, "1.5 billion adults, 20 and older were overweight. Among them, over 200 million men and nearly 300 million women were obese. Overall, more than 1 in 10 of the world's adult population were obese ". ${ }^{1}$ Based on the report of RISET KESEHATAN DASAR 2010 (RISKESDAS), the prevalence of overweight for adults more than 18 years in Indonesia was $10 \%$ and the prevalence of obesity for adults more than 18 years in Indonesia was $11.7 \%$ in accordance to the modified Asian Body Mass Index (BMI) cut-off points. Meanwhile, it also reports that the prevalence of overweight for West Java Region was $10 \%$ for year 2010, followed by prevalence for obesity which was 12.8 for year 2010 in accordance to the modified Asian BMI cut-off points. ${ }^{2}$ According to WHO, "Raised BMI is a major risk factor for non-communicable diseases such as cardiovascular diseases, diabetes, musculoskeletal disorders and cancer". ${ }^{1}$

Population assessment of Health Related Quality of Life (HRQOL) reported by Centers for Disease Control and Prevention (CDC) says that, HRQOL is "An individual's or group`s perceived physical and mental health over time". ${ }^{3}$ Based on CDC's report on HRQOL of United States residents, for the years 20062010 , there was $16.2 \%$ reported that having only fair or poor self-rated health. While, $7.0 \%$ of United State residents, reported that having 14 or more days of activity limitation for the period of 2006-2010..$^{4,5}$ Health Related

Correspondence: Sivanesan Supramaniyam, Faculty of Medicine, Universitas Padjadjaran, Jalan Raya BandungSumedang Km.21, Jatinangor, Sumedang, Indonesia, Phone: +628170208984 Email: s.sivanesan89@hotmail.com 
Quality of Life (HRQOL) is an important tool in identifying burden of diseases that can be prevented, injuries, and disabilities. The HRQOL data also may reveal the association between HRQOL and the risk factors. ${ }^{6}$

Overweight and obesity play a major role in an individual's HRQOL. Several studies have been done previously about the association between the BMI and HRQOL in Sweden, Korea, Singapore and China. Based on the Swedish study, the results show that overweight and obesity in adults from the age range of 1634 for male and female have a negative effect on physical components (PCS) and mental components (MCS) of health related quality of life but the there is a difference between the results according to the community. ${ }^{7-9}$ This shows that the HRQOL score in relation to BMI is sensitive to the community. The difference in the community may show significantly different results according the culture and beliefs of that particular population.

Therefore in this study the researcher intends to study the HRQOL score of normal, overweight and obese groups of the local population. The target population is undergraduates of Medical Faculty of Universitas Padjadjaran aged from 16 to 30 years old. This population was chosen based on the researcher's observation there are many undergraduates with overweight and obesity in the faculty. Moreover, this population also chosen because it shows the functionality level of the future doctors since they have a big role in treating people for long hours. So, the findings of the study can be used by the faculty to control overweight and obesity among its undergraduates to produce a future doctor who is competent physically and mentally.

\section{Methods}

Thestudy design was analytical cross-sectional conducted from September to November 2012 in Faculty of Medicine Universitas Padjadjaran, Jatinangor, Sumedang. The population of this study was male and female medical undergraduates of Universitas Padjadjaran. The inclusion criteria were the medical undergraduates of Universitas Padjadjaran in Jatinangor campus of the batch of 2009, 2010, 2011 and 2012 (Class A \& class B) who were willing to undergo screening process to measure their height and weight and to fill the questionnaire form. The exclusion criteria were students with chronic diseases.

The body weight and height measured
Table 1 The Weight Status Categories Associated with Body Mass Index in Adults

\begin{tabular}{ll}
\hline \multicolumn{1}{c}{ Body mass index } & \multicolumn{1}{c}{ Weight status } \\
\hline Below 18.5 & Underweight \\
$18.5-24.9$ & Normal \\
$25.0-29.9$ & Overweight \\
30.0 and Above & Obese \\
\hline
\end{tabular}

to calculate BMI of the students, which was computed from the rate of total weight in kilogram to square of height in meter, thus the measurement unit of BMI is $\mathrm{kg} / \mathrm{m} \neg 2$.

The overweight and obese subjects were selected using total sampling method, meanwhile the normal BMI were sampled using simple random sampling with equal number of subjects from the normal BMI is selected as a comparison group. All the samples are given guidance about the questionnaire and asked to fill the questionnaire sheet. The questionnaire is a validated questionnaire used worldwide for assessing HRQOL known as Medical Outcomes Study Short Form 36 (SF-36).

The HRQOL is the perception of the respondents about their health`s influence on their quality of life; measured in terms of the score based on their response to the SF36 form. The total score for the HRQOL is 100 . The SF-36 contains 36 items that can be generally classified into eight main domains of health namely Physical Functioning (PF), Role Physical (RP), Bodily Pain (BP), General Health (GH), Vitality (VT), Social Functioning (SF), Role-Emotional (RE) and Mental Health (MH). The scoring for each item is from 0 to 100 . Items with 6 options are scored as 100 , $80,60,40,20$ and 0 . Items with 5 options are scored from 100, 75, 50, 25 and 0. Meanwhile, items with 3 options are scored as 0,50 and 100 . Items with 2 options are scored as 0 or 100 . The mean score for each of 8 scales are calculated and compared between the normal, overweight and obese groups.

The correlation between the body mass index and HRQOL which recorder into the 8 HRQOL was analyzed using the Spearman`s Correlation.

\section{Results}

The analysis was restricted to the age 
Table 2 Number of the Respondents According to Gender and BMI status

\begin{tabular}{lcc}
\hline BMI status & $\begin{array}{c}\text { Male } \\
\text { (n=122) }\end{array}$ & $\begin{array}{c}\text { Female } \\
\text { (n=138) }\end{array}$ \\
\hline Normal & 46 & 84 \\
Overweight & 55 & 39 \\
Obese & 21 & 15 \\
\hline
\end{tabular}

Note: BMI, Body mass index

group of 16 to 30 years old. The total respondents that returned the questionnaire were 260 people out of 280 people who were selected after a thorough screening process. The non-response rate was $7.1 \%$.

Table 2 showed that most of subject was female, especially in norm weight group meanwhile in overweight and obese groups mostly male

The Spearman Correlation analysis method was used to study the relationship between the BMI status and HRQOL of the undergraduates. This was done by correlating the values of BMI with the scores of HRQOL of all the respondents.

\section{Table 3 Correlation between BMI and} HRQOL $(n=260)$

\begin{tabular}{|c|c|c|}
\hline Variables & $\begin{array}{l}\text { Spearman`s } \\
\text { rho }\end{array}$ & $\begin{array}{c}\mathrm{p} \\
\text { value }\end{array}$ \\
\hline $\begin{array}{l}\text { Health Related Quality } \\
\text { of Life (HRQOL) }\end{array}$ & -0.173 & $0.005^{*}$ \\
\hline $\begin{array}{l}\text { Physical Component } \\
\text { (PCS) }\end{array}$ & -0.188 & $0.002^{*}$ \\
\hline $\begin{array}{l}\text { Physical Functioning } \\
\text { (PF) }\end{array}$ & -0.285 & $0.000^{*}$ \\
\hline Role Physical (RP) & -0.074 & 0.236 \\
\hline Bodily Pain (BP) & -0.188 & 0.777 \\
\hline General Health (GH) & -0.133 & $0.032^{*}$ \\
\hline $\begin{array}{l}\text { Mental Component } \\
\text { (MCS) }\end{array}$ & -0.144 & $0.020^{*}$ \\
\hline Vitality (VT) & -0.194 & $0.002^{*}$ \\
\hline $\begin{array}{l}\text { Social } \\
\text { (SF) }\end{array}$ & -0.055 & 0.381 \\
\hline Role-Emotional (RE) & -0.121 & 0.051 \\
\hline Mental Health (MH) & -0.086 & 0.166 \\
\hline
\end{tabular}

Note: $p$-value $<0.05$, significant $(*)$

BMI, Body Mass Index
From this analysis, it was known that there was a negative correlation between the value of BMI and HRQOL score. Negative correlation in this case means that higher the values of BMI, the lower the HRQOL total scores. The Spearman correlation coefficient, rho $=$ -0.173 , significant at 0.05 level (table 3).

\section{Discussion}

From the results obtained the total score of HRQOL decreases as the BMI increases. So, it can be concluded thatthere is a negative correlation between the HRQOL and the BMI. But, not all the components of HRQOL are statistically significant for this negative correlation relationship between the HRQOL and BMI. The HRQOL can be divided into 2 main scales, namely PCS and MCS. The PCS includes components like physical functioning, role physical, bodily pain and general health. Meanwhile, MCS includes vitality, social functioning, role of emotional, and mental health components.

Physical functioning is a scale that measures the ability to perform activities of daily living and also strenuous activities. ${ }^{7}$ From this study, it can be concluded that both the male and female respondents had limitations in performing activities of daily living and strenuous activities as their body mass index increases. Obese group suffered the most from this limitation since the obese group is significantly different from the normal and overweight group based on the MannWhitney post hoc test. This is in accordance to a previous study on general population of Sweden where the obese respondents had significantly lower physical functioning score compared to the respondents with normal BMI. $^{7}$ There is no significant difference between the normal and overweight group suggesting that the normal and overweight group experienced relatively same level of limitations in performing daily activities and strenuous activities. This finding is in accordance to the study in China where the obese and pre-obese groups reported to have relatively same level of physical functioning score for male respondents.9 The female respondents of normal and overweight group showed no difference in physical functioning score maybe because the females of overweight group who are image sensitive have been frequently involved in regular exercise in order to get slim. So, this would have made strenuous activities much easier for them and had no difficulty in physical 
Table 4 SF-36 Scale and Summary Score (standard error) by BMI Category for Male and Female

\begin{tabular}{ccccc}
\hline & \multicolumn{4}{c}{ BMI } \\
\cline { 2 - 5 } & Normal & Overweight & Obese & K-W \\
\cline { 2 - 5 } & Median & Median & Median & p \\
\hline Health Related Quality of & 81.2 & 78.9 & $69.7^{* * *}$ & 0.005 \\
Life & & & & \\
Physical Component (PCS) & 86.9 & 86.3 & $77.2^{* * *}$ & 0.001 \\
Physical Functioning (PF) & 100.0 & 95.0 & $75.0^{* * *}$ & 0.000 \\
Role Physical (RP) & 100.0 & 100.0 & $100^{* * *}$ & 0.035 \\
Bodily Pain (BP) & 87.5 & 87.5 & 93.8 & 0.682 \\
General Health (GH) & 70.0 & 70.0 & $65.0^{*}$ & 0.057 \\
Mental Component (MCS) & 77.3 & 71.9 & $65.1^{*}$ & 0.028 \\
Vitality (VT) & 70.0 & $60.0^{*}$ & $62.5^{*}$ & 0.001 \\
Social Functioning (SF) & 77.5 & 77.5 & 76.3 & 0.591 \\
Role-Emotional (RE) & 100.0 & 100.0 & $66.7^{* * *}$ & 0.011 \\
Mental Health (MH) & 76.0 & 72.0 & 72.0 & 0.415 \\
\hline
\end{tabular}

* $\quad \mathrm{p}<0.05$ compare with normal BMI Group based on Mann-Whitney Post-Hoc test

** $\quad \mathrm{p}<0.05$ compare with overweight BMI Group based on Mann-Whitney Post-Hoc test

*** $\quad \mathrm{p}<0.05$ compare with normal \& overweight BMI Group based on Mann-Whitney Post-Hoc test

functioning.

Role- Physical reflects the extent that physical health has a limiting effect on work or other activities. ${ }^{7}$ In this study, there is no correlation between the role-physical and BMI of the respondents. However, the obese group is significantly different from the overweight and normal BMI group for male and total respondents. This is in accordance to the previous study where the score of role-physical in obese group is significantly different from the normal group. ${ }^{7}$ Meanwhile, in female respondents, there is no any significant difference amongthe groups which is in accordance to the previous study. ${ }^{7}$ The possible reason for no correlation is possibly the age group of the respondents. Body Mass Index (BMI) usually influences the physical health in long-term, for example, in adults of 40 plus of age. While, in this sample, the respondents are aged from 16-30 years old, causing the BMIhas no effect on the physical health.

Bodily pain concerns the amount of pain felt and whether it interferes with normal activities. ${ }^{7}$ In this study, there is no correlation between the bodily pain and BMI of the respondents. Moreover, there is no significant difference between the groups based on the
Kruskal-Wallis test in males, females and total respondents as they experienced relatively same level of interference in normal activities due to body pain regardless of their body mass index status. This finding is in contrary to the findings from a previous study, where the bodily pain score is significantly different between the obese group and normal group.7 This finding is might be related to the role of the respondents as students. The bodily pain arises when an individual with excess body weight involved in stressful or hectic environment such as working environment. These undergraduates are less challenged in terms of physical, so showing no difference between the different BMI groups.

General health measures perceived general health status. ${ }^{7}$ From this study, it can be concluded that as the body mass index of the respondents increases, the overall general health becomes worsen. However, there is no significant difference for male, female and total respondents; between the normal, overweight and obese groups of this study. This finding is in contrary to the findings from a previous study where the general health score is significantly different between the obese group and normal group. ${ }^{7}$ The contradicting result may be due to the respondents since the respondents are 
medical students and the awareness towards general health maintenance is higher.

"Vitality measures the level of energy and tiredness among the respondents". ${ }^{7}$ From this study, it can be concluded that the level of energy is decreased and respondents tend be more tired as the body mass index increases. For the male and total respondents, there is a significant difference between the normal and overweight group. Meanwhile, there is also a significant difference between the normal and obese group. This is in accordance to a previous study on general population of Sweden where the obese respondents had significantly lower vitality score compared to the respondents with normal BMI. ${ }^{7}$ But, there is no significant difference between the overweight and obese group suggesting that the level of energy between the overweight and obese respondents relatively same. Meanwhile, for female respondents, there is no significant difference between the BMI groups. The same results were obtained among the women for vitality score in the research in Sweden. ${ }^{7}$

Social functioning concerns how social activities are affected by physical health or emotional problems. ${ }^{7}$ In this study, there is no correlation between the social functioning and BMI of the respondents. Moreover, there is also no significant difference between the groups for male, female or total respondents. It shows that the social activity involvement due to physical or emotional problems is relatively same among the respondents of normal, overweight and obese groups. Based on the Swedish study, the male respondents had significant difference between the groups for social functioning in contrary to the results of this study; while the female respondents had no significant difference between the groups which is in accordance to this study. ${ }^{7}$ The respondents show no difference in social functioning because body mass index has no effect on their physical health and emotional problems, because medical students are capable of taking care of their physical health and also capable of overcoming emotional problems without any impact to their social life since they are specially trained to have good communication skills as a future doctor.

Role-emotional reflects the extent that work or other activities are limited by emotional problems. ${ }^{7}$ From this study, it can be concluded that there is no correlation between the body mass index and role-emotional scale. Although there is no correlation, there is a significant difference between the obese to overweight and between normal to obese groups for male and total respondents. Meanwhile, for female respondents there is no significant difference between the groups which is in accordance to the previous study. ${ }^{7}$ The respondents show no difference in role-emotional because the medical students are capable of overcoming emotional problems without any impact to their activities or routines.

Mental health measures the emotional well being oftherespondents. ${ }^{7}$ thereisnocorrelation between the BMI of the respondents and mental health. This shows that the emotional well being of all the respondents are relatively same regardless of their body mass index. This is also true based on the study of the general population of Sweden and China, where there is no significant difference in the scores of mental health scale between the groups of normal, overweight and obesity for male and female respondents. ${ }^{7,9}$ Limitation of this study were we did not consider other factors except gender as influencing factors. From this study, it can be concluded that increased body mass index impairs the health related quality of life of the respondents, except in scales such as bodily pain, social functioning and mental health.

\section{References}

1. WHO. Fact sheet No 311: Obesity and overweight. [Downloaded in 5 May 2012] Available at: http://www.who.int/ mediacentre/factsheets/fs311/en/index. html.

2. Badan Penelitian dan Pengembangan Kesehatan Kementerian Kesehatan RI. Laporan Riset Kesehatan Dasar 2010. Kementerian Kesehatan Republik Indonesia; 2010.[ Downloaded in 5 May 2012] Available at: http://www.litbang. depkes.go.id/sites/download/buku_ laporan/lapnas_riskesdas2010/Laporan_ riskesdas_2010.pdf.Centers for Disease Control and Prevention. Measuring healthy days: population assessment of healthrelated quality of life. Atlanta, Georgia: CDC; 2000 [ Downloaded in 2 May 2012] Available at: http://www.cdc.gov/hrqol/ pdfs/mhd.pdf.

3. Centers for Disease Control and Prevention. Health-Related Quality of Life. 2012; [Downloaded in 2 May 2012] Available at: http://apps.nccd.cdc.gov/HRQOL/TrendV. asp? State $=1$ \& Category $=1 \&$ Measure $=8$. CDC. Health-Related Quality of Life. 2012; [Downloaded in 2 May 2012] Available at: 
http://apps.nccd.cdc.gov/HRQOL/TrendV. asp? State $=1 \&$ Category $=1 \&$ Measure $=1$.

4. CDC.HRQOLConcepts. 2011; [Downloaded in 2 May 2012] Available at: http://www. cdc.gov/hrqol/concept.htm.

5. Larsson U, Karlsson J, Sullivan M. Impact of overweight and obesity on health-related quality of life--a Swedish population study. Int J Obes Relat Metab Disord 2002; 26(3):417-24.

6. Wee HL, Cheung YB, Loke WC, Tan CB, Chow $\mathrm{MH}$, Li SC, et al. The association of body mass index with health-related quality of life: an exploratory study in a multiethnic Asian population. Value Health. 2008; 11 Suppl 1:S105-14.

7. Wang R, Wu MJ, Ma XQ, Zhao YF, Yan XY, Gao QB, et al. Body mass index and healthrelated quality of life in adults: a population based study in five cities of China. Eur J Public Health; 22(4):497-502.

8. CDC. BMI for Adults. 2011 [updated 13 September 2011]; [Downloaded in 2 May 2012] Available at: http://www.cdc.gov/ healthyweight/assessing/bmi/adult_bmi/ index.html. 